\title{
Influence of heat-treatment on the dynamic behavior of 3D laser-deposited Ti-6Al-4V alloy
}

Jin Yao ${ }^{1}$, Tao Suo ${ }^{1,2, *}$, Shuangyin Zhang ${ }^{1,2}$, Feng Zhao ${ }^{3}$, Hongtao Wang ${ }^{4}$, Jiabin Liu ${ }^{4}$, Yuzeng Chen ${ }^{5}$, Yulong $\mathrm{Li}^{1,2}$

${ }^{1}$ School of Aeronautics, Northwestern Polytechnical University, Xi'an 710072,Shaanxi, PR China

${ }^{2}$ Fundamental Science on Aircraft Structural Mechanics and Strength Laboratory, Northwestern Polytechnical University, Xi'an 710072,Shaanxi, PR China

${ }^{3}$ The Peac Institute of Multiscale Sciences, Chengdu610031, Sichuan, China

${ }^{4}$ Institute of Applied Mechanics, Zhejiang University, Hangzhou 310027, Zhejiang, PR China

${ }^{5}$ State Key Laboratory of Solidification Processing, Northwestern Polytechnical University, 710072 Xi'an,Shaanxi, PR China

${ }^{*}$ Corresponding author:Tao Suo

Mail address: P. O. Box 118, 127 Youyi Xilu, Xi'an 710072, Shaanxi, PR China

Tel.: +86-29-8849-4859; fax: +86-29-8849-1208

E-mail: suotao@nwpu.edu.cn

\section{ABSTRACT}

In order to understand the influence of heat treatment on the mechanical property of 3D laser-deposited Ti-6Al-4V alloy, uniaxial compressive experiments were performed on the heat-treated 3D laser-depositedTi-6Al-4V and its as-deposited 
counterpart under both quasi-static and dynamic loading. Meanwhile, the microstructure observation was also carried out on both as-received and deformed alloys. Based on the experimental results, the influence of heat treatment on microstructure evolution of as-deposited 3D laser-deposited Ti-6Al-4V alloy and the mechanical behaviors such as flow stress, strain hardening rate, strain rate sensitivity and fracture mechanism were investigated in detail. The results indicate that the heat treatment could improve both yield stress and compressive strength of the 3D laser-deposited Ti-6Al-4V alloy, but the plasticity of the heat-treated alloy decreased if compared with the as-deposited alloy. Moreover, remarkable strain softening was also observed in the heat-treated 3D laser-deposited Ti-6Al-4V alloy at strain rates of 1500 and $3000 \mathrm{~s}^{-1}$. Microstructure observations indicated the occurrence of adiabatic shear localization may be the main reason for strain softening.Compared with deformation twins of heat-treated Ti-6Al-4V alloy formed under the quasi-static loading, the adiabatic shear band under the dynamic loading was characterized with equiaxed nanograins induced by dynamic recrystallization.

Keywords: 3D laser-deposited Ti-6Al-4V; heat treatment; microstructure; mechanical behavior

*Corresponding author:suotao@nwpu.edu.cn 


\section{Introduction}

Due to its excellent high specific strength, toughnessand good corrosion resistance, Ti-6Al-4V is one of the most widely usedtitanium alloys in engineering structures. Its combination of specific weight and mechanical properties (evenat high temperatures) has promoted thewide applicationsof Ti-6Al-4V in the aeronautics and astronautics industries[1]. However, its poormachinability leads to high wasting ratio of material, high cost, long manufacturing time as well as the difficulty in fabrication of complex structures. Therefore, additive manufacture technologies such as the $3 \mathrm{D}$ laser-depositedmethod have been employed to manufacture the Ti-6Al-4V alloy components.However, because of the special layered microstructure the mechanical behavior of additive manufacture components may be significantly different from their conventionally manufactured counterparts [2].Compared with the wrought material, the formation of acicular microstructure due to the high cooling rates in the additive manufacture process can result in reduced ductility[3]. At the same time, the yield and ultimate tensile strength of the additive manufacture material were also found to be slightly lower than the forged Ti-6Al-4V alloy [4]. Therefore, one key issue for the 3D laser-depositedmanufactured Ti-6Al-4V alloy components is to achieve comprehensive performance by controllingthe microstructure. Beyond control the parameters of the forming process, usually, heat treatment is a widely acceptedmethod to optimize the microstructure of the as-deposited material. In the past several years, plenty ofresearches have been carried out to investigate the effectof heat treatment on the mechanical propertiesof the 3D laser-deposited titanium alloy. 
The results indicated thatthe heat treatment would influence the transformation of the metastable martensite in the as-deposited 3D laser-deposited Ti-6Al-4V alloy [5].Meanwhile, the solution treatment time and temperature, aging treatment time and temperature played an important rolein the microstructure of 3D laser-depositedtitanium alloy [6].In case of the heat treatment temperature below $\beta$-transustemperature, the original martensite $\alpha$ 'phase would transform to a lamellar mixture of $\alpha$ and $\beta$ phases. On the contrary, extensive grain growth occurred and large $\beta$ grains formed which transformedto lamellar $\alpha+\beta$ uponcooling [7]. The latest experiments by Zheng et al [8] indicated that, compared with the as-casted Ti-6Al-4V plates, the mechanical properties of 3D laser-deposited Ti-6Al-4V plates were significantly improved after rolling. Moreover the followed annealing not only released the residual stress in the post heat treatment alloy significantly, but also resulted inremarkable improvement inelongation without obvious reduction in ultimate tensile strength[8].

It's well known that the observed plastic deformation resistance or flow stress of metals and alloys depends on the microstructure of the material as well as the strain rate and temperature associated with the loading.Thus, investigations on the strain rate and temperature sensitivity of metallic materials are necessary for extending our understanding about mechanical properties of materials, among which the fully understanding of deformation behavior at high strain rates isof great importance in such dynamic conditions as high-speed machining,high-velocity impact,metal forming, penetration, explosive-metal interaction.Unfortunately, limited literatures 
focused on the dynamic behavior of 3D laser-deposited alloys (limited to the authors' knowledge). Although the recent work by Li et al [10] did show different dynamic behaviors between the as-casted 3D laser-deposited Ti-6Al-4V alloy and the forged alloy, investigation of the effect of heat treatment on the dynamic behavior of $3 \mathrm{D}$ laser-deposited Ti-6Al-4V alloy is still open.

In the present work, aim to understand the influence of heat treatment on the dynamic behavior of 3D laser-deposited Ti-6Al-4V, experiments on the uniaxial compressive behavior of 3Dlaser-deposited Ti-6Al-4V both before and after heat treatment at the strain rates ranging from $10^{-3}$ to $3000 \mathrm{~s}^{-1}$ were performed at room temperature. The fracture mechanism of the heat-treated 3D laser-deposited Ti-6Al-4V alloy was also observed via optical microscopy, scanning electron microscope (SEM) and transmission electron microscope (TEM).

\section{Materials preparation and experimental procedure}

\subsection{Material preparation}

In this work, the raw 3Dlaser-deposited Ti-6Al-4V alloywasprovidedby the StateKeyLaboratoryofSolidification Processingin NorthwesternPolytechnicalUniversityofChina.The composition of the Ti-6Al-4V titanium alloy powder and the detailed parameters of laser solid forming process are listed in Table 1 and 2 respectively. The materials used in this experiment consist of a titanium substrate and spherical Ti-6Al-4V powders with the size of -100 to +150 mesh. Before deposition, the powders were dehumidified at $393 \mathrm{~K}$ under the condition of vacuumto avoid the influence of moisture absorption of powders on forming 
quality. Meanwhile, in order to reduce the influence of surface defects, before deposition the surface of the substrate was grinded with the abrasive sand paperand etchedusing a solution of absolute ethyl alcohol and acetone.During the forming process, the Ti-6Al-4V alloy powders were put into the melt pool by the lateral feeding nozzle powder feeder. In order to prevent the powders from oxidation during forming process, the forming process was carried out in ambient atmosphere with a local argon shielding device.

Table 1 Composition of the Ti-6Al-4V titanium alloy powder (wt \%)

\begin{tabular}{ccccccccc}
\hline $\mathrm{H}$ & $\mathrm{O}$ & $\mathrm{N}$ & $\mathrm{C}$ & $\mathrm{Si}$ & $\mathrm{Fe}$ & $\mathrm{V}$ & $\mathrm{Al}$ & $\mathrm{Ti}$ \\
\hline 0.01 & 0.21 & 0.046 & $\leq 0.056$ & $\leq 0.039$ & $\leq 0.15$ & 4.00 & 6.02 & others \\
\hline
\end{tabular}

Table 2 The parameters of laser solid forming

\begin{tabular}{ccccccc}
\hline Laser & Scanning & Powder & Flux of & Laser spot & Over lap & Increment \\
powder & speed & feeding rate & shielding & diameters & ratio & of $Z$ \\
$(\mathrm{w})$ & $(\mathrm{mm} / \mathrm{s})$ & $(\mathrm{g} / \mathrm{min})$ & Gas $(\mathrm{L} / \mathrm{h})$ & $(\mathrm{mm})$ & $(\%)$ & $(\mathrm{mm})$ \\
\hline $2000 \sim 2700$ & $2 \sim 10$ & $3 \sim 10$ & $120 \sim 200$ & 3 & $30 \sim 50$ & $0.3 \sim 0.5$ \\
\hline
\end{tabular}

Samples for metallographicand mechanical testing were cut from the center of the as-depositedblock by wire-electrode cutting. Thesurfacesboth parallel and vertical to thedeposition direction (denoted as side view and top view respectively, see in Fig. 1) were chosen for the metallographic observation by using a Zeiss Supra55 Field Emission Scanning Electron Microscope (SEM) and a JEM-2100 transmission 
electron microscope (TEM) operating at 200kV.Before subjected to microstructure observation, the 3D laser-deposited Ti-6Al-4V alloy were firstly grindedby using SiC grinding papers with the grit size from 360 to 2000.After that, the grinded samples were mechanically polishedwith $\mathrm{Cr}_{2} \mathrm{O}_{3}$ suspensionand subsequently corroded with etching reagent (with the specification of $\left.\mathrm{HF}(1 \sim 3 \mathrm{~mL})+\mathrm{HNO}_{3}(2 \sim 6 \mathrm{~mL})+\mathrm{H}_{2} \mathrm{O}(100 \mathrm{~mL})\right)$
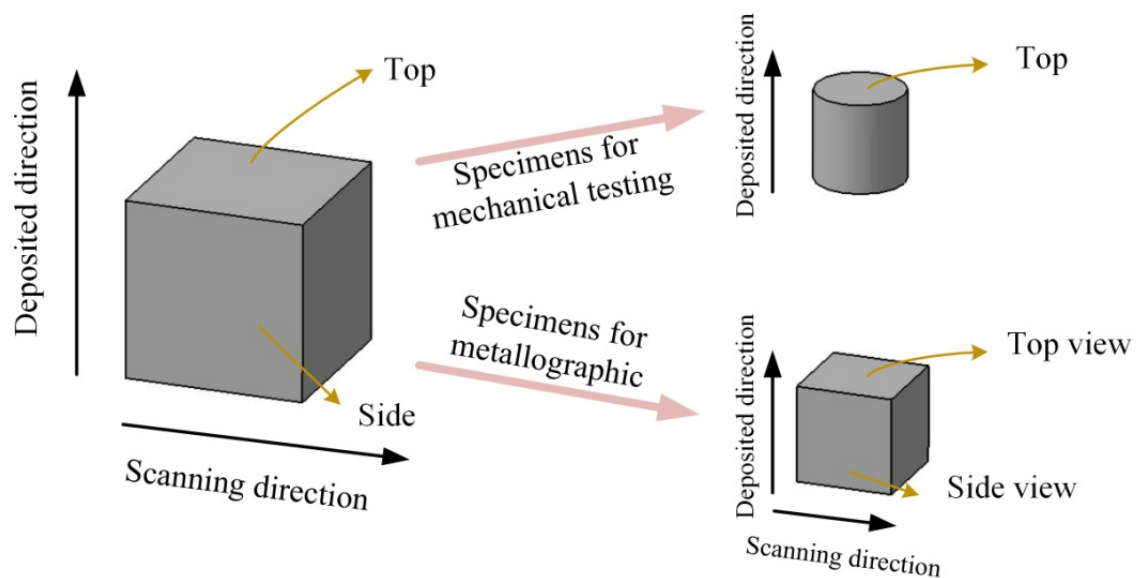

Fig. 1 Schematic illustration of samples preparation for mechanical testing and metallographic

In order to understand the influence of heat treatment on the dynamic behavior of 3D laser-deposited Ti-6Al-4Valloy, before microstructure observation and mechanical testing some of the specimens were also subjected tosolution treatment at $1223 \mathrm{~K}$ for 4 hours followed by air cooling (AC) firstlyand then aging treated at 873K for 2 hours followed byair cooling.

\subsection{Mechanical testing}

Mechanical tests were conducted on both the as-deposited and heat-treated material. The specimens were cut into cylinders with both the diameter and length of $5 \mathrm{~mm}$. The axial direction of the cylinder was parallel to deposition direction of the 
alloy block, as shown in Fig. 1. The quasi-static compressive experiments were performed using an electronic universal testing machine.During the tests, the strain rate was controlled at about $10^{-3} \mathrm{~s}^{-1}$. The split Hopkinson pressure bar (SHPB) was employedfor the high strain rate experiments.According to the one dimensional elastic stress wave theory, the strain, stress and strain rate of tested specimen can be calculated as[11, 12]:

$$
\begin{gathered}
\sigma_{\varepsilon}=E\left(\frac{A}{A_{S}}\right) \varepsilon_{T} \\
\varepsilon_{\mathrm{S}}=\frac{2 C_{0}}{l_{S}} \int_{0}^{t} \varepsilon_{R} d \tau(2) \\
\dot{\varepsilon}_{\mathrm{S}}=\frac{2 C_{0}}{l_{S}} \varepsilon_{R}(3)
\end{gathered}
$$

where $\varepsilon_{R}$ and $\varepsilon_{T}$ are the reflected pulse and transmitted strain pulses measured by strain gages mounted on the input and output bars. $C_{0}, E$, and $A$ denote the longitudinal elastic wave velocity, Young's modulus and cross-sectional area of the two long elastic loading bars respectively. $l_{S}$ and $A_{S}$ are the length and cross-sectional area of the specimen respectively. The strain rates of the dynamic experiments were 500,1500 and $3000 \mathrm{~s}^{-1}$ respectively.

\section{Results and discussion}

\subsection{Microstructure observation of as-deposited and heat-treated materials}



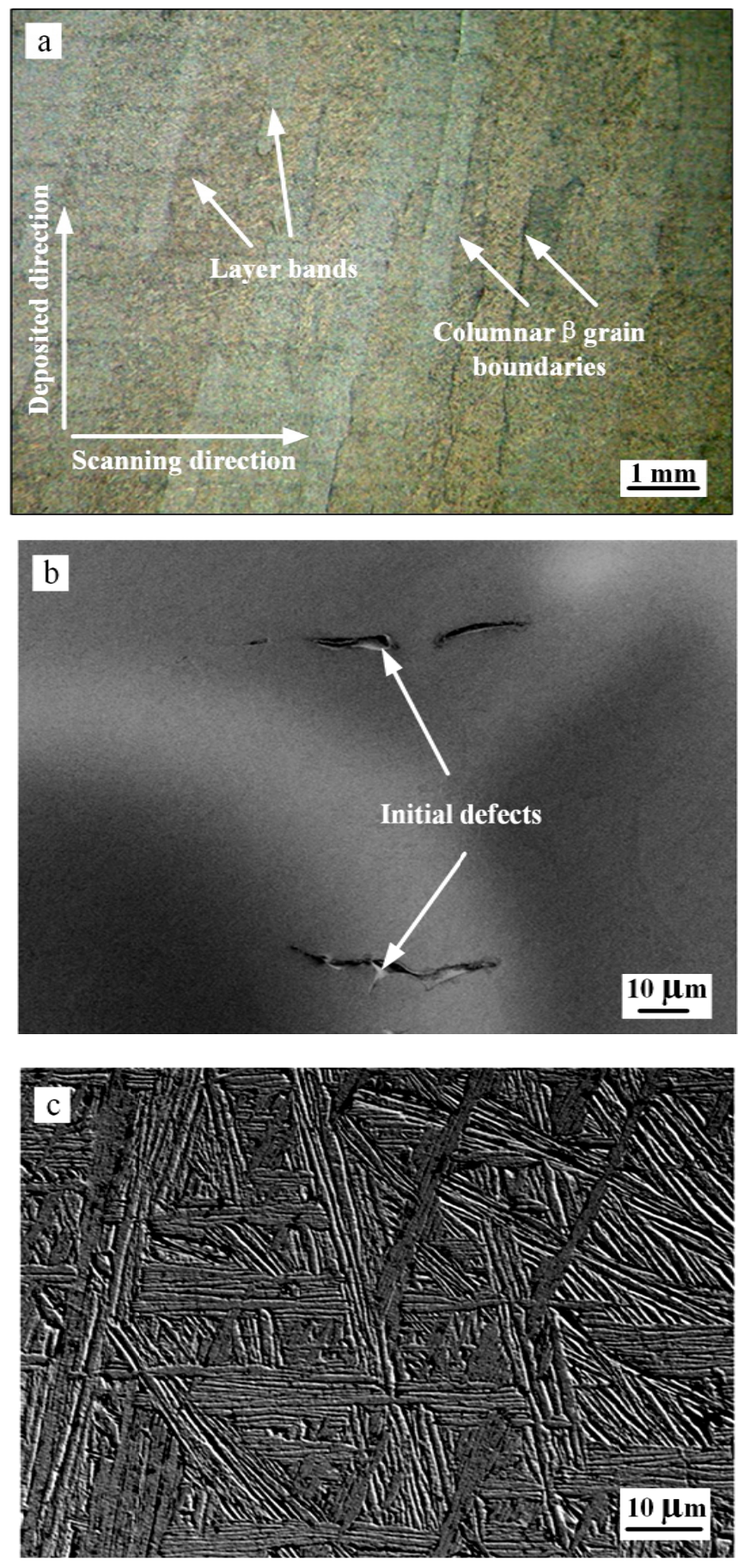


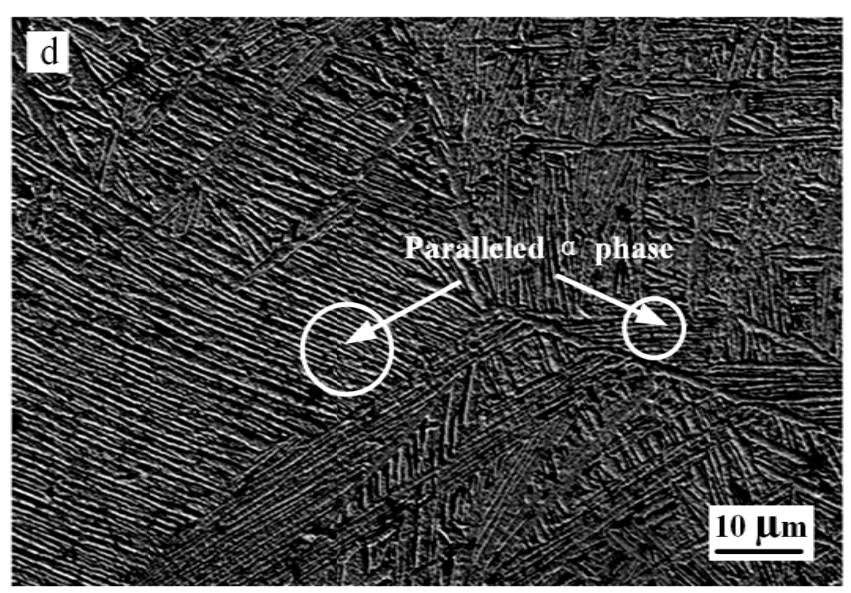

Fig.2. Microstructure of the as-deposited Ti-6Al-4V alloy (a) Side view by optical microscope, (b) the defects on the side surface (parallel to deposition direction), (c) by SEM, (d) top view by SEM.

Fig.2 (a) and (b) show the typical side-view microstructure of the as-deposited Ti-6Al-4V alloy in low magnification by optical microscope and SEM respectively. It can be seen from Fig.2(a)that the as-deposited Ti-6Al-4V alloy presents the characteristic of light and shade strips, indicating different crystallography orientations. Some horizontal layers bands (the horizontal dark lines in the Fig.2(a)) between adjacent deposited layers can also be observed clearly, which is caused by the re-melting and re-solidification of the material during the deposition of subsequent layers [13].Some continuously epitaxial priorcolumnar $\beta$ grains with the length up to several millimeters and traversing several deposited layers are also visible. These columnar $\beta$ grainsgrew along the deposited direction and inclined towards the scanning direction, as shown in Fig.2 (a). The average width of themwas measured to be about $0.5 \mathrm{~mm}$. Side view of the as-deposited Ti-6Al-4V alloy by SEM(see in Fig.2(b)) showsthat there are also some initial defects which is believed to be due tothe lower temperature of the molten pool resulted frombeing fed too much powers 
or too fast scanning speed.Fig.2(c) and (d) showthe typical microstructures of side view and top view of the as-deposited Ti-6Al-4V alloy by SEM. It can be seen from Fig.2(c) and (d), the microstructures present the characteristics of little acicular $\alpha$ phases and a lot of Widmanstätten $\alpha$ laths.In Fig.2(d), the $\alpha$ Widmanstättenlath structuresat the boundary of the prior $\beta$ grains with an averaged width of about $0.1 \mu \mathrm{m}$ are paralleled to each other, which are generally referred to as $\alpha$-Ti clusters.However, within the $\beta$ grains, in the region away from the grain boundaries the Widmanstätten $\alpha$ lath structures change to basket-weaveprogressively,as shown in Fig.2(c).
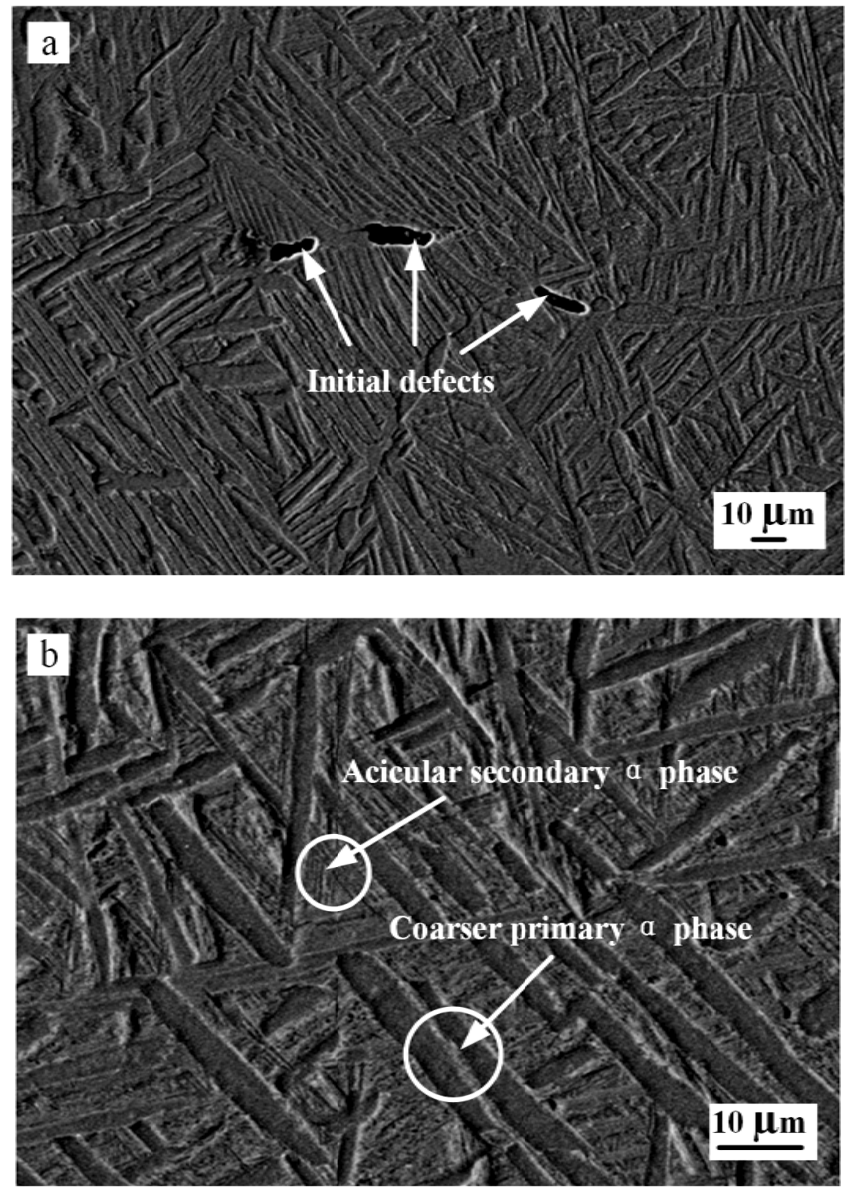

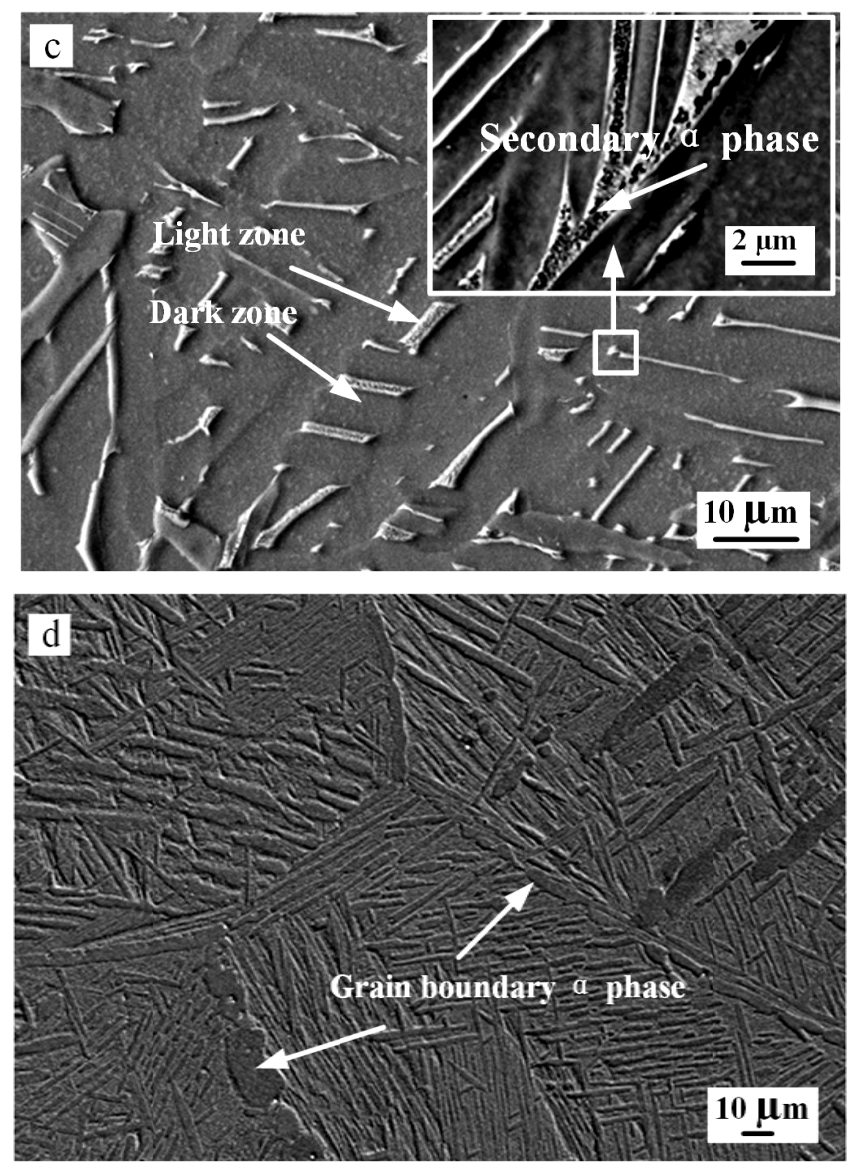

Fig.3.Microstructure of the heat-treated Ti-6Al-4V alloy (a) the defects on the side surface, (b) and (c) side view by SEM (for (c) light zones are $\beta$ phase, the dark zones are $\alpha$ phase), (d) top view by SEM

Fig.3 shows the typical microstructure of 3D laser-deposited Ti-6Al-4V alloy after heattreatment.Defectscan still be found from the side view (see in Fig.3 (a)), indicatingthe heattreatment cannot eliminate the microstructure defectscompletely. The heat-treated 3D laser-deposited Ti-6Al-4V alloy displays a basket-weave microstructure with intricately mixed multiple variants of alath (see in Fig.3 (b)).Meanwhile, although the primary $\alpha$ phasesbecame coarser and shorter, plenty of acicular secondarya phases forming duringsolution heattreatmentare found to 
precipitate in the prior $\beta$ phase.During the following aging treatment, these metastable phases transformed into stable and diffusedsecondaryaphases.From the insert of the Fig.3(c), it can be clearly seen that these secondary aphases present a basket-weave microstructure and the grain width is ranging from100 300nm. Moreover, the boundaries of prior $\beta$ grains also become coarserand the boundariesare no longer continuousas a result of the growth of $\alpha$ phases, as shown in Fig.3(d). It should be pointed out that these coarse $\alpha$ phases(no matter at the boundaries of the grains or in the grains) may lead to the reduction in plasticity of the heat-treated material.

\subsection{Stress versus strain response}

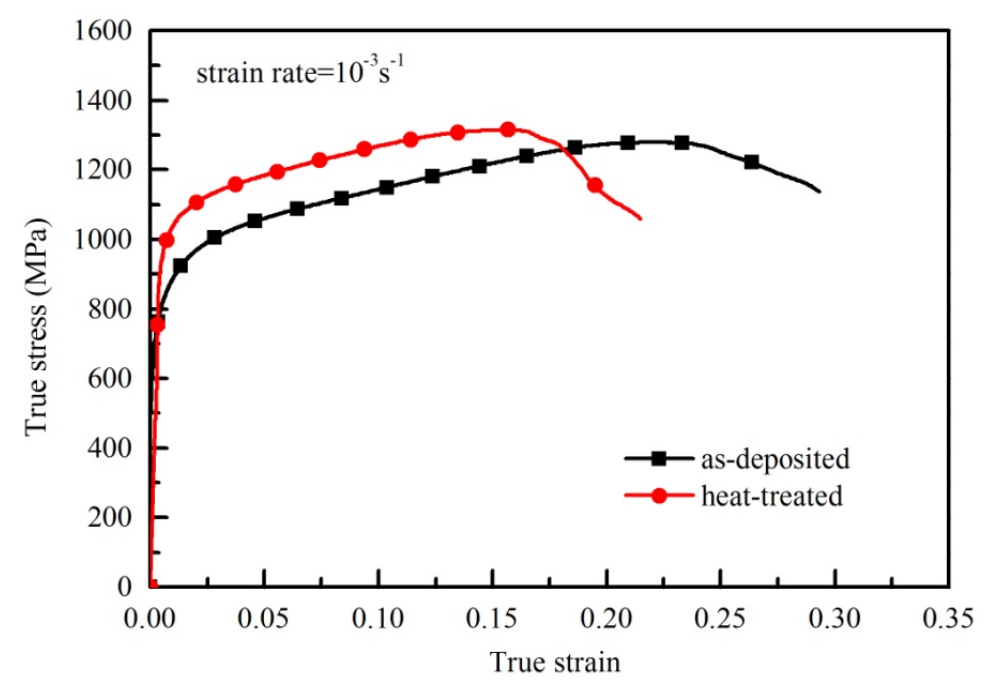

(a) $10^{-3} \mathrm{~s}^{-1}$ 


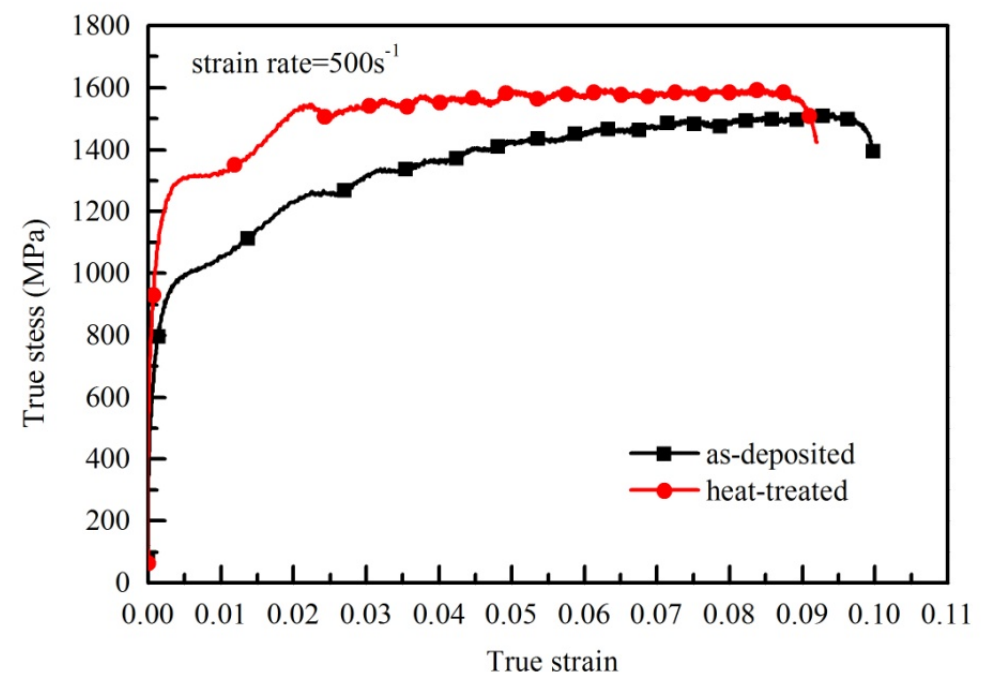

(b) $500 \mathrm{~s}^{-1}$

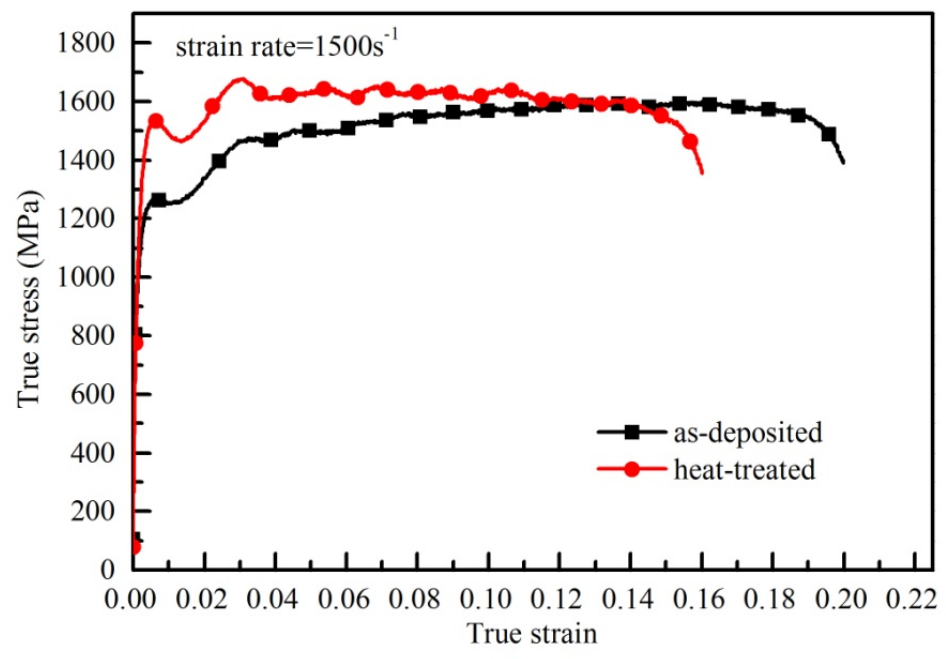

(c) $1500 \mathrm{~s}^{-1}$ 


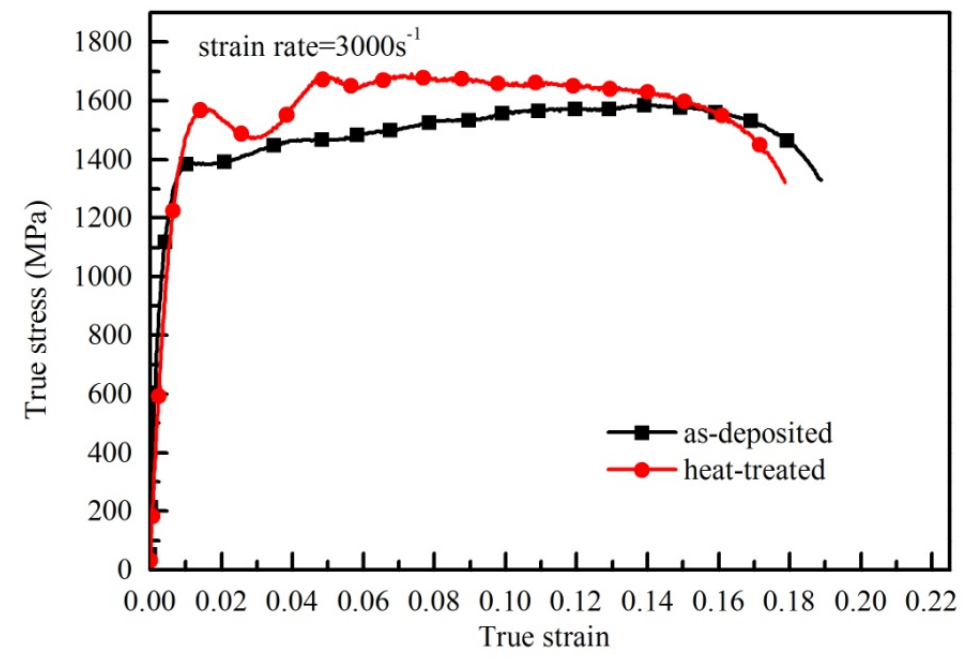

(d) $3000 \mathrm{~s}^{-1}$

Fig.4.True stress-strain curves of the as-deposited and heat-treated Ti-6Al-4V alloy at different strain rates (a) $10^{-3} \mathrm{~s}^{-1}$, (b) $500 \mathrm{~s}^{-1}$, (c) $1500 \mathrm{~s}^{-1}$ and (d) $3000 \mathrm{~s}^{-1}$

The true stress-strain curves of both the as-deposited and heat-treated 3D laser-depositedTi-6Al-4V alloy tested at roomtemperature and at different strain rates are shown in Fig. 4. Compared with its as-deposited counterpart, remarkable enhancement in flow stress can be observed for heat-treated 3D laser-depositedTi-6Al-4V alloy under both quasi-static and dynamic loading. However, the heat treatment seems to also have negative effect on the plasticity of the 3D laser-depositedTi-6Al-4V alloy. The tiny and diffuse basket-weave nano-scale secondary aphasesprecipitated in the prior $\beta$ phases were believed to play an important role in enhancement of the 3D laser-depositedTi-6Al-4Valloy[14]. In the prior $\beta$ grains, these precipitated secondary $\alpha$ phases may hinder the motion of moving 
dislocations, thus leading to increment of strength.However, those coarse primary $\alpha$ phases formed due to heat treatmentmay weaken the plasticity of the heat-treated 3D laser-depositedTi-6Al-4V alloy.

Except the influence on strength and plasticity of 3D laser-depositedTi-6Al-4V alloy, the heat treatment also affects the work hardening behavior of the material. Compared with the as-deposited alloy for which remarkable strain hardening is observed at all tested strain rates, the strain hardeningrate of the heat-treated alloy varies with the increase of applied strain rate. At the strain rate of $0.001 \mathrm{~s}^{-1}$ (see in the Fig.4(a)), the heat treatment seems to have no effect on the strain hardening behavior of the 3D laser-depositedTi-6Al-4V alloy. However, under dynamic loading (see in the Fig.4(b), (c) and (d)), the strain hardening rate of the heat treated 3D laser-depositedTi-6Al-4V alloy is observed to decrease remarkably if compared with its as-deposited counterpart. Interestingly, at the strain rates of 1500 and $3000 \mathrm{~s}^{-1}$, remarkable work hardening (as for the heat-treated material)is only observed at the very early stage of plastic deformation. After that, the work hardening capability is close to being exhausted and strain softeningis even observed as the true strain exceeds about 0.05(see in Fig.4(c) and (d)).

\subsection{Strain hardening rate}




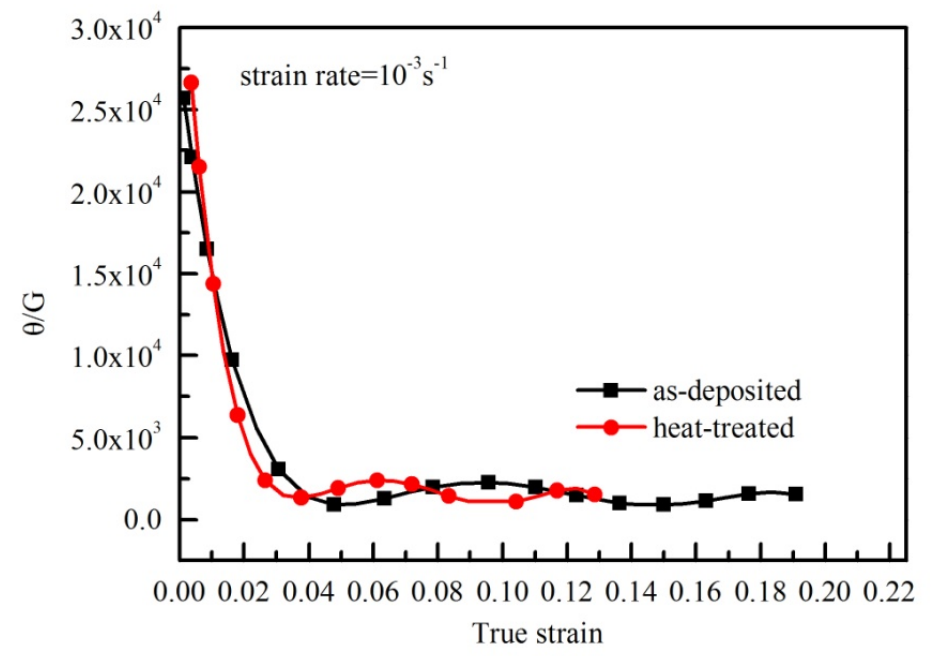

(a) $10^{-3} \mathrm{~s}^{-1}$

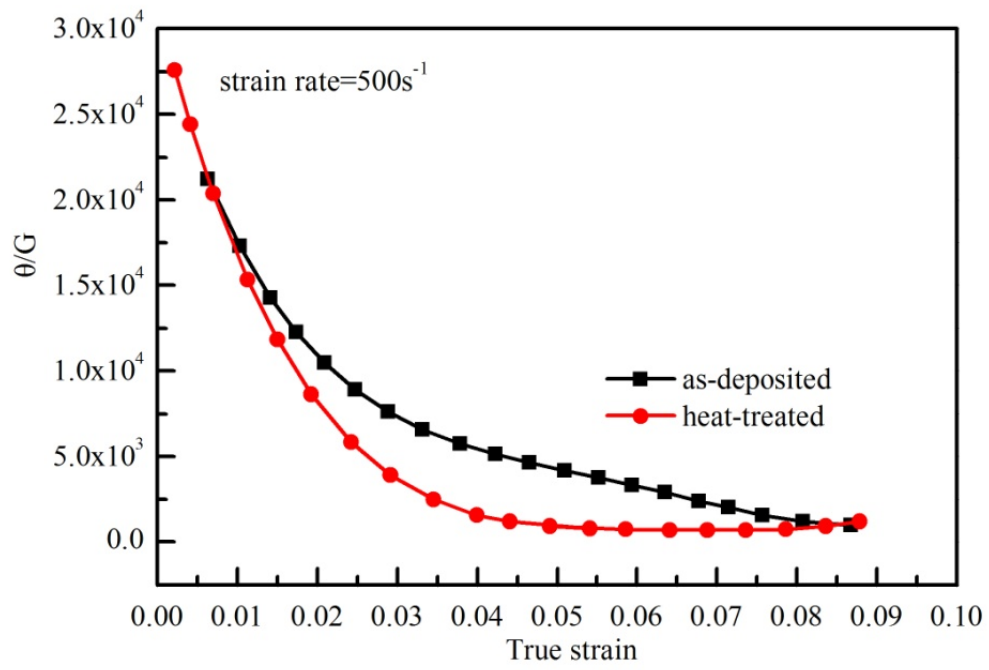

(b) $500 \mathrm{~s}^{-1}$ 


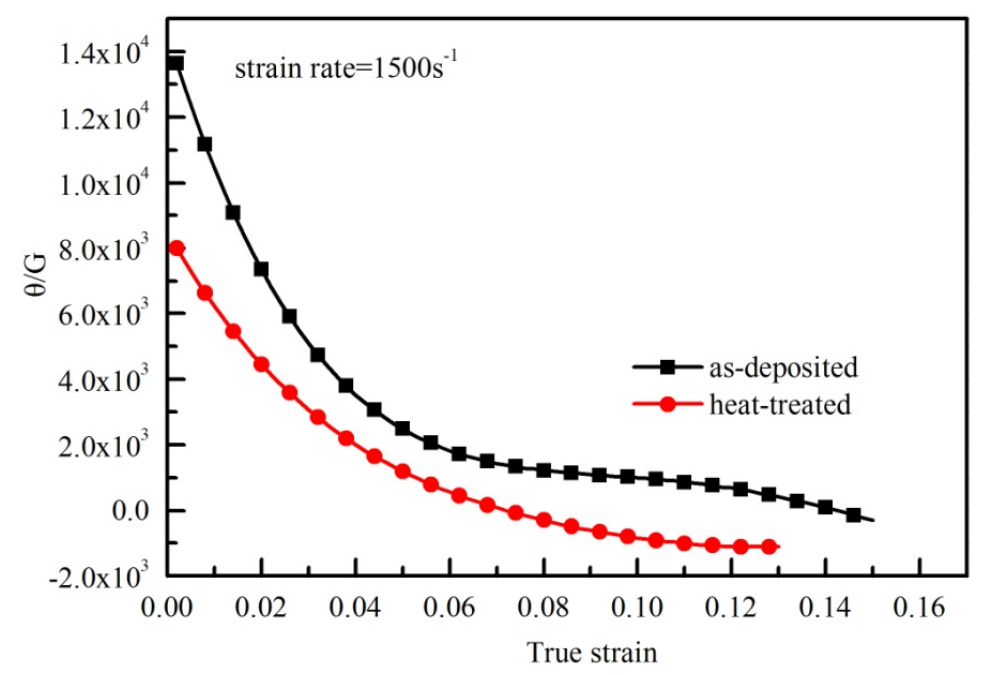

(c) $1500 \mathrm{~s}^{-1}$

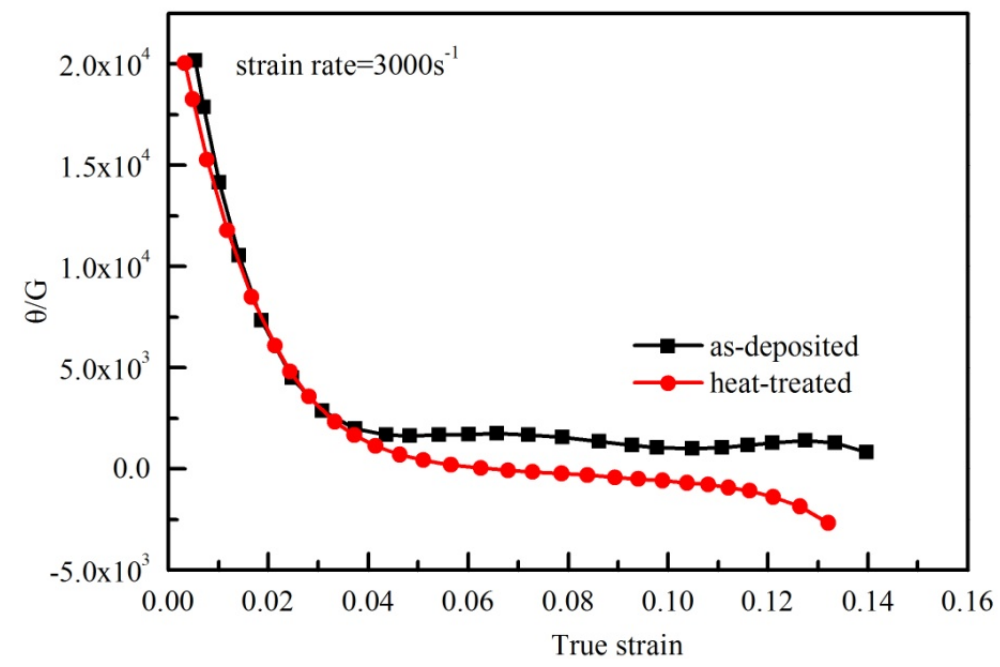

$3000 \mathrm{~s}^{-1}$

Fig.5. Strain hardening rate of materials at different strain rate (a) $10^{-3} \mathrm{~s}^{-1}$ (b) $500 \mathrm{~s}^{-1}$ (c) $1500 \mathrm{~s}^{-1}$ (d) $3000 \mathrm{~s}^{-1}$

To qualify the strain hardening behavior of materials, the strain hardening 
rate(defined as $\mathrm{d} \sigma / \mathrm{d} \varepsilon$, where $\sigma$ and $\varepsilon$ are true stress and true strain respectively) versus true strain curves for both as-deposited and heat-treated laser-deposited Ti-6Al-4V alloy at different strain rates are plotted in Fig.5(a)-(d). The results show that the strain hardening rate for both materials decreases rapidly with increasing strain during the early stages of plastic deformation. After this stage, the as-deposited Ti-6Al-4V alloy undergoes a long deformation stage in which the strain hardening rate varies slightly with plastic deformation. No matter at quasi-static or at dynamic state, the as-deposited Ti-6Al-4Valloy always displays positive strain hardening rate. Contrasted with the as-deposited Ti-6Al-4V alloy, the heat-treatedTi-6Al-4V alloy displays positive strain hardening rate at the strain rates of $10^{-3}$ and $500 \mathrm{~s}^{-1}$, but shows a negative trend at the strain rates of 1500 and $3000 \mathrm{~s}^{-1}$. This fact is usually attributed to the adiabatic thermal softening or shear localization under dynamic loading conditions, which counteract the strain hardening and strain rate hardening effect [15]. A factworth mentioned is that during plastic deformation, it was accepted that no more than $10 \%$ of the plastic work can be stored as the internal energy while the other generates heat which is either dissipated in case of quasi-static loading or is used to increase the temperature of the deformed material[16]. If the heat generation rate is greater than that of dissipation, sample's temperature increases. Under quasi-static loading, as there is enough time for the heat induced by plastic deformation to diffuse through the small specimens $\left(\Phi 5 \times 5 \mathrm{~mm}^{3}\right)$, the plastic work induced temperature rise in the material can be neglected. While under dynamic loading, for example $1500 \mathrm{~s}^{-1}$, since the deformation process is within several microseconds, the heat does not have 
enough time to dissipateto surroundings and will lead to the increase of specimen temperature consequentially. That is to say, the stress versus strain curves achieved dynamically are actually adiabatic lines on which the corresponding temperature increases with strain level [12].It is well known that the increment of temperature usuallycauses the decrease of flow stress, named as thermal softening. Thus the plasticdeformation at high strain rates is dominated actually bythe competition between the thermal softening caused by adiabatictemperature rise and enhanced work hardening dueto the high applied strain rate.

Usually, the temperature rise in specimens deformed at high strain rate can be calculated by
$\Delta T=\frac{\beta}{\rho C_{V}} \int_{0}^{\varepsilon} \sigma d \varepsilon$
(4)where $\rho$ is the density of material(for Ti-6Al-4V,

$\rho=4.51 \mathrm{~g} / \mathrm{cm}^{3}$ ), $C_{\mathrm{V}}$ is the specific heat (for Ti- $6 \mathrm{Al}-4 \mathrm{~V}, \mathrm{C}_{\mathrm{V}}=578 \mathrm{~J} / \mathrm{kgK}$ ), $\sigma$ is the true stress, cis the true strain and $\beta$ is a constant, taken to be 0.9 , as suggested in Ref.[16]. Fig.6 shows the adiabatic temperature rise for specimens deformed at the strain rates of 500, 1500 and $3000 \mathrm{~s}^{-1}$ respectively. It can be seen that the temperature rise increases with strain level and applied strain rate. Within true strain 0.15 , the maximum temperature rise for both the as-deposited and heat-treated material is no more than $90 \mathrm{~K}$. Considering the facts that the strain hardening capability is still kept even as the adiabatic temperature rise reaches almost $90 \mathrm{~K}$ for theas-deposited alloy and relative high melting temperature of Ti-6Al-4V (1883K) as well, the adiabatic temperature is proposed to may not be the main reason for the strain softening of heat-treated laser-deposited Ti-6Al-4V. 


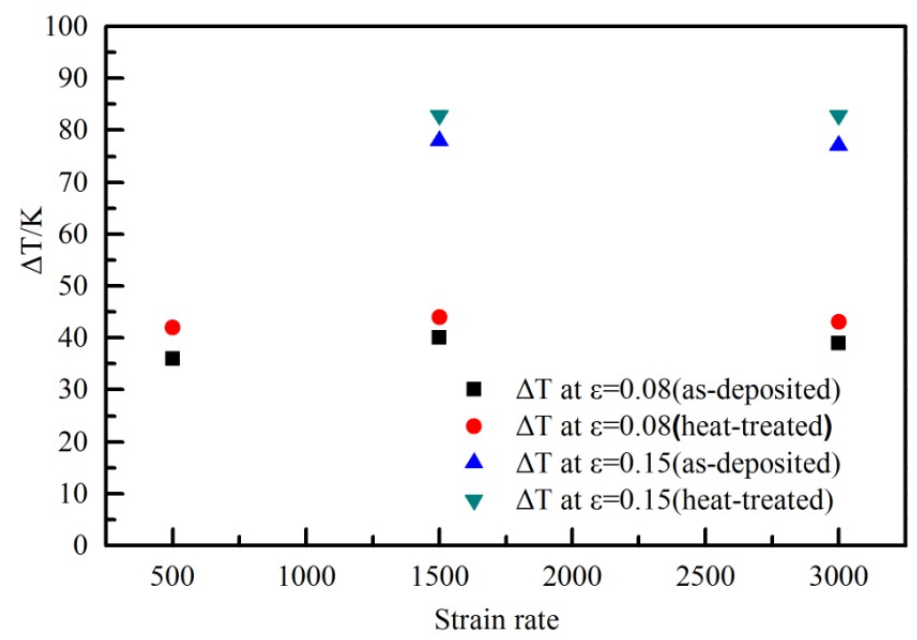

Fig.6. Temperature rise of specimens deformed at high strain rates $\left(500 \mathrm{~s}^{-1}, 1500 \mathrm{~s}^{-1}\right.$ and $\left.3000 \mathrm{~s}^{-1}\right)$

\subsection{Strain rate sensitivity}

Despite the microstructural characteristics, the observedplastic deformation resistances or flow stresses of metals andalloys also depend on the rate associated with loading[17].From the stress-strain curves at different strain rates of the as-deposited and heat-treated alloy (see in Fig.7), it can be seen that with the increase of the strain rate the flow stress presents an increasing trend. It's worth mentioning that the fact the maximum strain at the strain rate of $500 \mathrm{~s}^{-1}$ is only about $10 \%$ is simply due to the limited duration of loading wave applied to the specimens. 


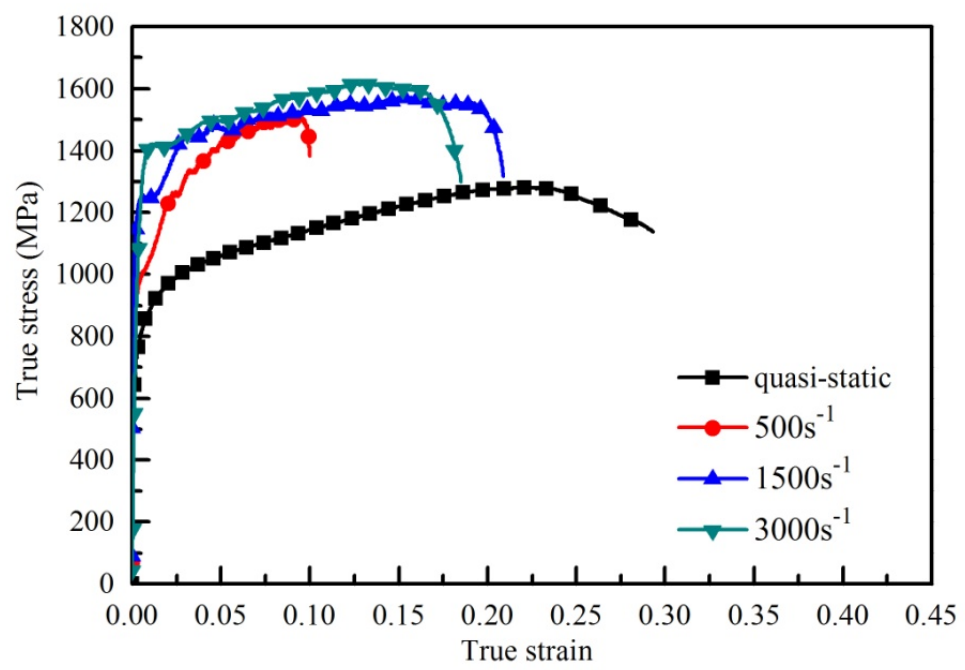

(a) as-deposited

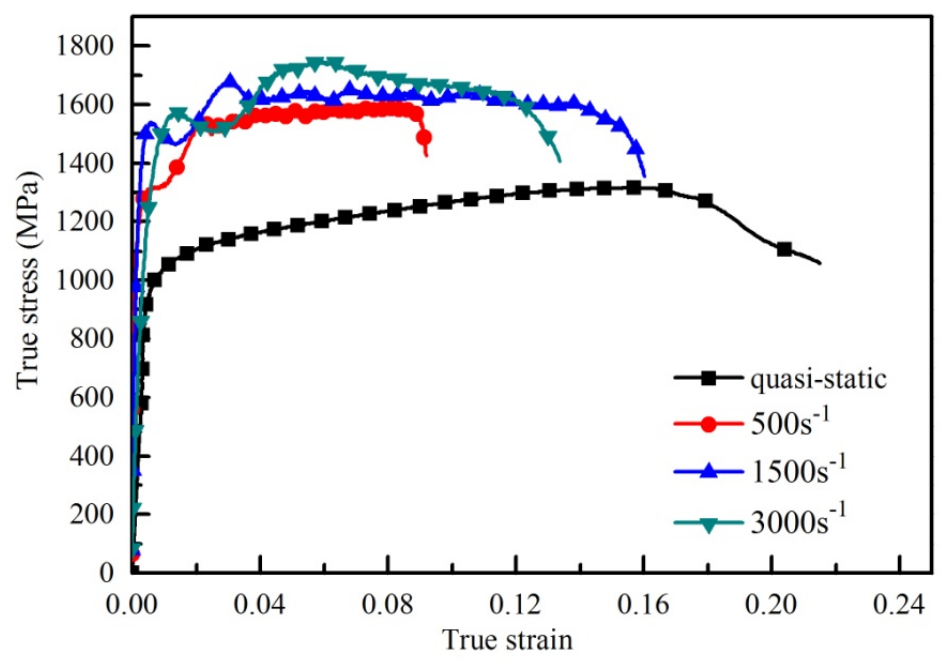

(b) heat-treated

Fig.7. True stress versus true strain curve of different strain rates at room temperature (a) as-deposited (b) heat-treated

To quantify the strain rate sensitivity of materials, the SRS parameter $m$ is 
usually defined as

$$
m=\left(\frac{\partial \ln \sigma}{\partial \ln \dot{\varepsilon}}\right)_{\varepsilon}
$$

where $\dot{\varepsilon}$ is the applied uniaxial strain rate. Actually, the value of $m$ should be a function of applied strain. As it's unpractical to estimate the SRS at every strain level, it is often given in the form of values at certain fixed strains. It should be noticed that the $m$ as defined in Eq.(5) should be measured for a fixed microstructure state of the material. Thus, strain rate jump or stress relaxation tests are normally employed to determine its value[18]. Occasionallythe values of SRS can also be determined approximately by using log-log flow stress versus strain rate plots at a certain strain from which $m$ was derived astheslopeofalinearregressionfit[19]. In the present work, SRS values, 0.022 and 0.019 for as-deposited and heat-treated Ti-6Al-4Valloy respectively, were determined using the latter methodat the plastic strain of $8 \%$ (see in Fig. 8). Obviously, it seems the process of heat treatment can suppress the strain rate sensitivity of the 3D laser-deposited Ti-6Al-4V alloy to a certain extent.

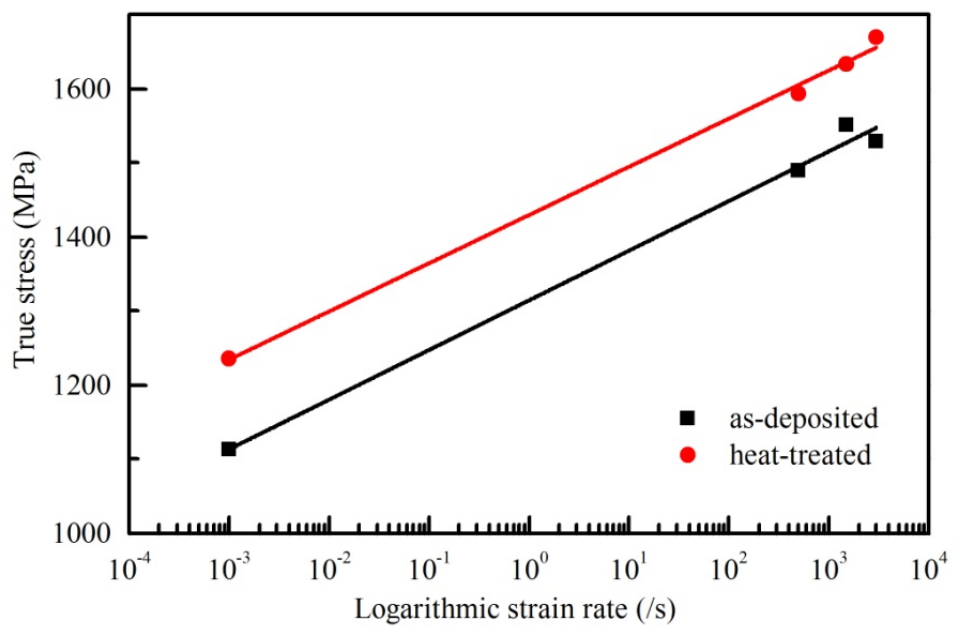


Fig. 8 The function of true stress at true strain of $8 \%$ versus strain rate plot for both as-deposited and heat-treated 3D laser-deposited Ti-6Al-4V alloy

\subsection{Fracture morphology and microstructure in localized shear band}

\subsubsection{Fracture morphology for as-deposited and heat-treated alloy}

As mentioned in section 3.2, it seems that the adiabatic temperature may not be the main reason for the strain softening observed in present test.Therefore, one possible reason for such phenomenon might be adiabatic shear localization. It is widely accepted that the materials with high flow stresses, high thermal sensitivity, small strain hardening and small SRS are more susceptible to adiabatic flow localization under dynamic compression. A flow localization parameter, $\alpha$, which is afunction of the strain-hardeningrate $\gamma$ and the strain rate sensitivity $m$, can be used to qualitatively estimatethe propensity of ametal toflow localization $[20,21]$.A quantitative description of agives the following equation:

$$
\alpha=(\gamma-1) / m
$$

where ris given by $(1 / \sigma) /(\partial \sigma / \partial \varepsilon)$ into which the thermaleffect can be included. From the Eq.(6), an increasingaindicates higher susceptibility toshear localization.Therefore, apositiveyand decreased $m$ will favor flow localization. Inthe case of compressive deformation in which both the stress and strain are negative, a positive $\gamma$ correspondsto flow softening in stress-strain curve.In Fig.5, it has shown that the strain-hardeningrate $\gamma$ for the heat-treated material compressed at strain rates above $1500 \mathrm{~s}^{-1}$ substantiallydecreases to negative, indicating the higher susceptibilityto 
adiabatic shear localization if compared with its as-deposited counterpart. To further understand the mechanism for strain softening at high strain rates and confirm the occurrence of adiabatic shear localization, the post-deformed specimens with failure were subjected to the microstructure observations. It should be noticed that, for the as-deposited Ti-6Al-4V alloy, the macro failure was not observed under the quasi-static loading condition. However, although a crackwas found in the heat-treated sample tested quasi-statically,the specimen did not rupture completely and two parts were still bonded together. At the strain rate of $500 \mathrm{~s}^{-1}$, failure did not occur for both as-deposited and heat-treated Ti-6Al-4V alloy due to the limited duration of loading wave. Therefore, the fracture morphology was only observed for both the as-deposited and heat-treated material deformed at the strain rates 1500 and $3000 \mathrm{~s}^{-1}$ (see in Fig.9(a)-(d)). It can be seen from Fig. 9(a)-(d) that two typical areas(dimple and smooth areas)withdifferent features are alternatelydistributed on the whole fracture surface of the as-deposited material, indicating the occurrence of adiabatic shear failure in the tested specimens[14]. It is commonly accepted that fracture occurring in adiabatic shear bands is not uniform and ultimate ruptures resulted from ductile and brittle fracture modes. The dimpleswhich usually exhibit ductile fracture characteristicare believed to originate from generation andcoalescenceof voids. However, for the smooth areas, it exhibits brittle fracture characteristic. If comparing the fracture surfaces of the heat-treated alloy with those of as-deposited alloy, the smooth area for the heat-treated material is much larger than that of as-deposited alloy, and fewer dimples are observed on the fracture surface of 
the heat-treated alloy. Meanwhile, both the length and depth of dimples on the fracture surface of the heat-treated alloy are shorter, indicating the relative poor ductility of the heat-treated alloy.
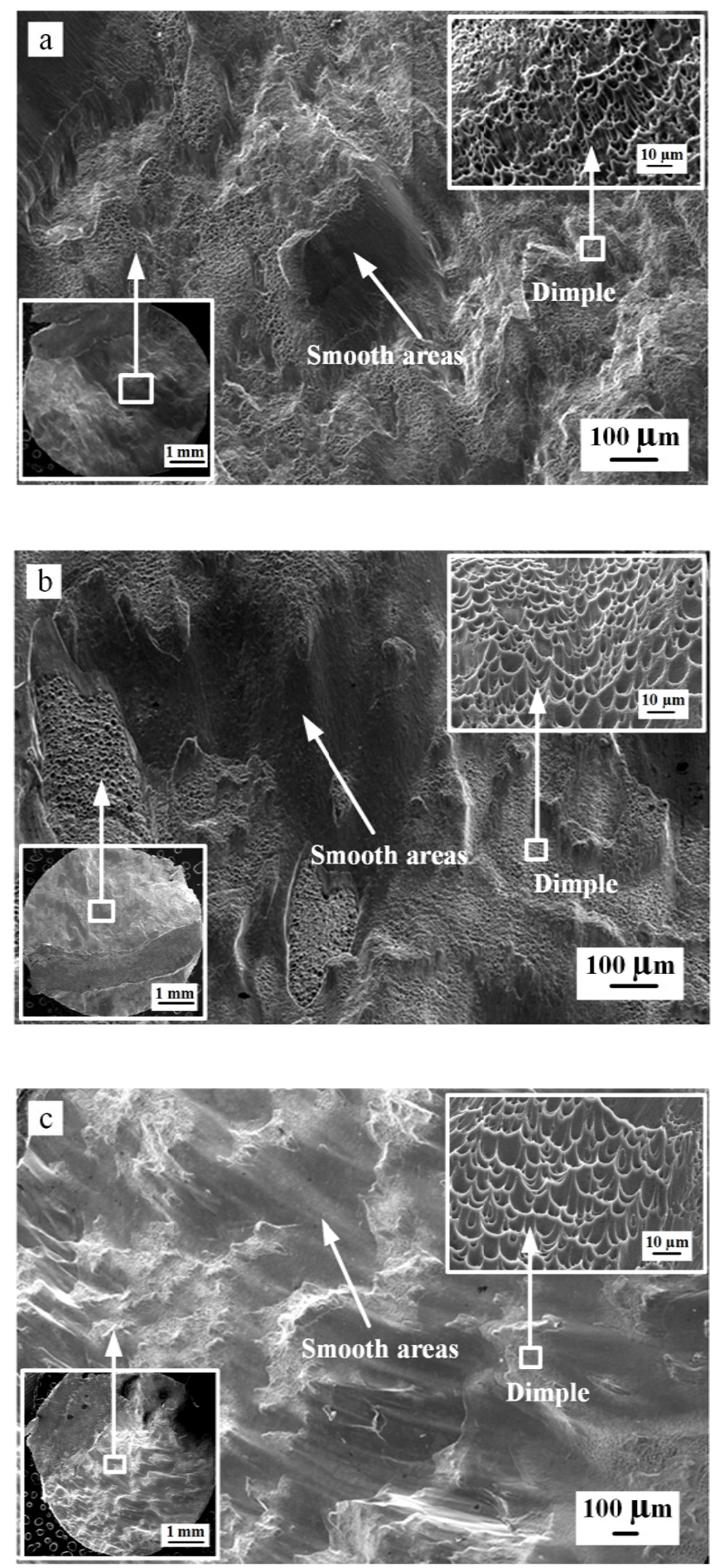


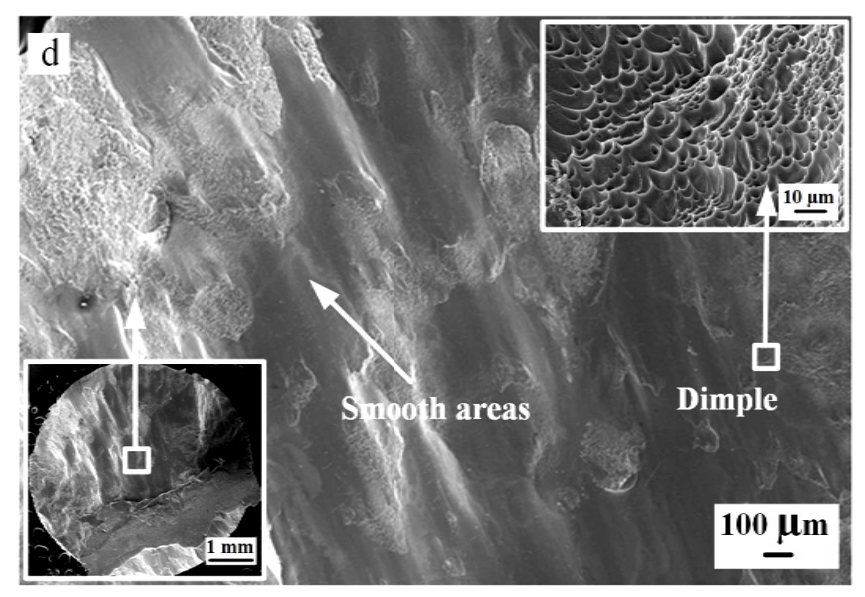

Fig. 9 Fracture morphology of Ti-6Al-4V alloy after dynamic compression (a) as-deposited alloy at the strain rate of $1500 \mathrm{~s}^{-1}$, (b) heat-treated alloy at the strain rate of $1500 \mathrm{~s}^{-1},(\mathrm{c})$ as-deposited alloy at the strain rate of $3000 \mathrm{~s}^{-1}$, (d) heat-treated alloy at the strain rate of $3000 \mathrm{~s}^{-1}$

\subsubsection{Microstructure in localized shear band of heat-treated alloy}

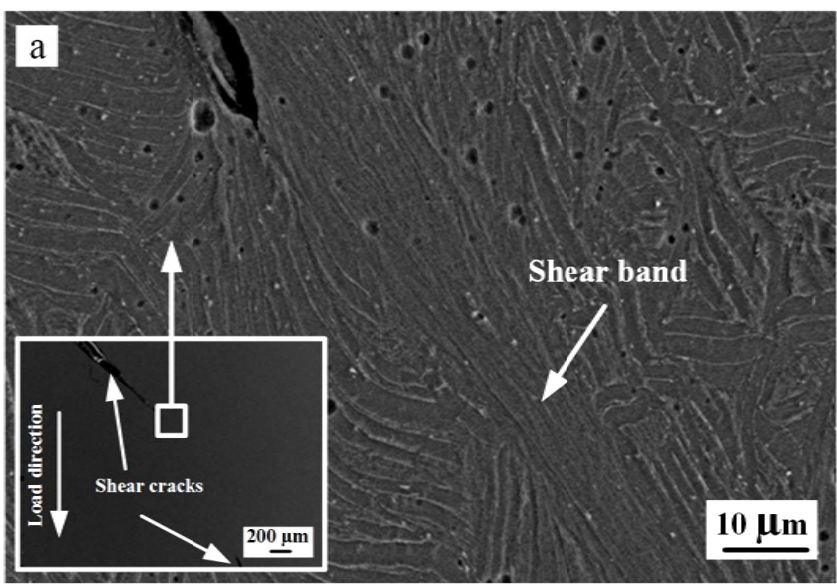




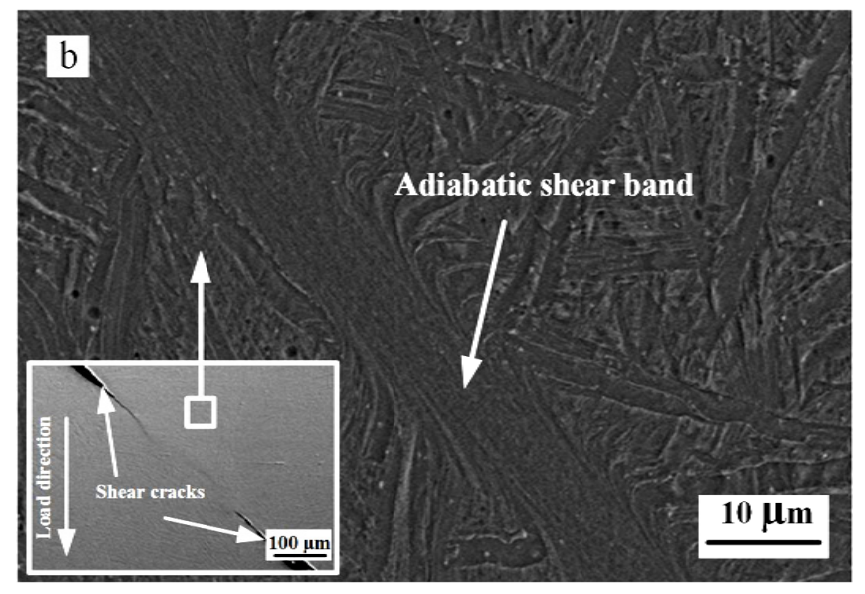

Fig.10 SEM micrographs of shear band of the heat-treated alloy after quasi-static and dynamic compression (a) quasi-static (strain rate of $10^{-3} \mathrm{~s}^{-1}$ ), (b) dynamic(strain rate of $1500 \mathrm{~s}^{-1}$ )

Shear bands, in the form of band-likeregions of concentrated plastic flow, are one of themost frequently observed failure models in titanium alloys. They are characterized bymassive localized shear plastic flow in a narrow deformation band while the abutting matrix undergoescomparably homogeneous flow. For titanium alloys which are commonly thought to have high susceptibility to shear localization, failure induced by shear band can be frequently observed even under uniaxial compressive load [22-24]. In the present work, as mentioned above, except that the heat treatment is supposed to not only enhance the 3D laser-deposited Ti-6Al-4V alloy but also weaken the plasticity to a certain extent, the susceptibility to shear localization is also believed to be increased after the as-deposited material was subjected to heat treatment. If compared with the as-deposited Ti-6Al-4V alloy which show shear failure only at high strain rates, macro shear failure even occurred as the heat-treated material suffered from quasi-static compression (see in Fig.10), indicating more susceptibility to shear localization of the heat-treated alloy. 
For better understanding the mechanism of shear failure in the heat-treated Ti-6Al-4V alloy, two specimens, deformed at 0.001 and $1500 \mathrm{~s}^{-1}$, with a macro shear crack not rupturing completely (as seen in Fig. 10(b)) were collected for TEM observation of the microstructure inside the shear band. It should be pointed out that due to the limited size of shear band between the tips of two macro cracks, the thin foil of TEM samples were prepared with focused iron beam (FIB) technology directly. The procedure of preparation of ASB's TEM sample is shown in Fig.11.

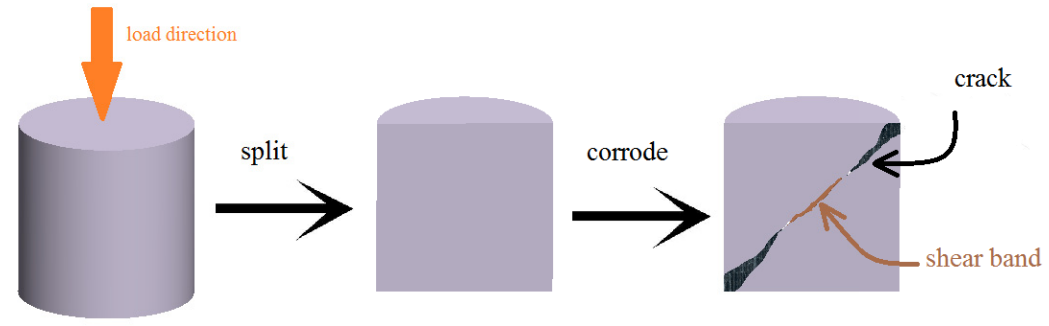

Fig. 11 Schematic illustration of TEM sample preparation using FIB
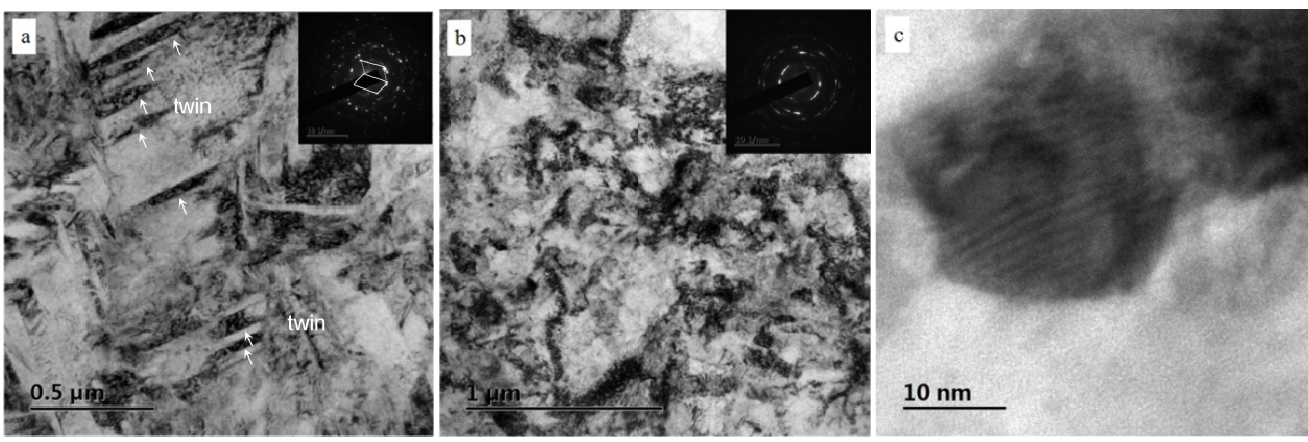

Fig. 12 TEM observation of microstructure inside the shear band for heat-treated specimens

$$
\text { deformed at the strain rate of (a) } 0.001 \mathrm{~s}^{-1} \text {, (b) and (c) } 1500 \mathrm{~s}^{-1}
$$

Fig.12 shows the TEM observation of the localized shear band for specimens deformed at 0.001 and $1500 \mathrm{~s}^{-1}$ respectively. Some parallel band-like structures with the length ranging from about 100 to $500 \mathrm{~nm}$ can be clearly found in the severe shear 
deformation band of specimen compressed under the quasi-static loading. They are considered to be deformation twins which were often observed in titanium alloy [25]. It is an evidence that below a critical strain rate, due to the low symmetry of hexagonal close-packed (HCP) structure, the plastic deformation of Ti-6Al-4V alloy is given priority to deformation twinning. Surprisingly, in adiabatic shear band formed at $1500 \mathrm{~s}^{-1}$, although it is commonly accepted that the susceptibility to deformation twinning during plastic deformation increases with the strain rate, high density of dislocation are observed while the deformation twins seem to be restricted. The discontinued ring-like selected area diffractionpattern (as shown in Fig.12 (b)) also indicates that a large number of tinyequiaxed grains with high-anglegrain boundaries exist within adiabatic shear band. Moreover, the high resolution TEM observation does show tiny and dislocation-free nano-sized grains with the grain size no more than $20 \mathrm{~nm}$ within the adiabatic shear band. The features that the shear band consists of fine recrystallized grains are very similar to those observed in a large number of metals and alloys deformed at high strain rates [26,27]. Traditionally, the formation of the ultrafine and equiaxedgrains in the adiabatic shear band should be attributed to the dynamic recrystallization mechanism which bases on the dislocation theory.However, the formation of the ultrafine and equiaxedgrains in the metals with HCP structure is associated with dislocationslipping and twinning, which was proposed as twining-induced rotational dynamicrecrystallization mechanism [28, 29].These dynamic recrystallizations induced tiny grains are thought to be accompanied by asudden reduction in the dislocation density, and finally lead to an 
instant softening[30-32]. Therefore, the twining-induced rotational dynamic recrystallization is suggestedto be the main deformation mechanism for initiation andpropagation of adiabatic shear band in the heat-treated 3D laser-deposited Ti-6Al-4V alloy in case of dynamic deformation [31].

\section{Summary and conclusion}

In this work, we have carried out the uniaxial compressive experiments on as-deposited and heat-treated 3D laser-deposited Ti-6Al-4V alloy under both quasi-static and dynamic loading conditions at room temperature.Based on the experimental results and microstructure observation, the influence of heat treatment on the mechanical behavior of 3D laser-deposited Ti-6Al-4V alloy was analyzed.It is observed that the microstructure of the as-deposited Ti-6Al-4V alloy consists of the columnar prior $\beta$ grains with an average grain width of about $0.5 \mathrm{~mm}$, which grow epitaxially from the substrate along the deposited direction. At the boundaries ofßgrains, thereare mainly Widmanstättenlath $\alpha$ phases parallel to each other. However, after heat treatment, the microstructure consists of basket-weave microstructure with intricately mixed multiple variants of alaths, and the primary $\alpha$ phase became coarser and shorter.Meanwhile, there are plenty of acicular secondary $\alpha$ phase precipitation in the prior $\beta$ phase after the material was heat treated.Whenever the materials were compressed under quasi-static or dynamic loading, the strength of the heat-treated 3D laser-depositedTi-6Al-4V alloy was enhanced. However, the heat treatment has negative effect on the plasticity deformation capacity of 3D laser-depositedTi-6Al-4V alloy. It is proposed that the coarse $\alpha$ phase are the main reason for the reduction in 
plasticity of the heat-treated material whilethose nano-sizedsecondary aphasesin the prior Bgrainplay an important role enhancement. Meanwhile, the process of heat treatment can suppress the strain rate sensitivity of the 3D laser-deposited Ti-6Al-4V alloy but lead to higher susceptibility of adiabatic shear localization to a certain extent. Severe shear deformation band, in which some parallel deformation twins with the length ranging from about 100 to $500 \mathrm{~nm}$ can be clearly found, was observed for heat-treated specimen compressed under the quasi-static loading. When the heat-treated material was compressed at the strain rates of 1500 and $3000 \mathrm{~s}^{-1}$, adiabatic shear localizationis observed. Microstructure observation on deformed specimens indicates that high density of dislocations exist within the adiabatic shear band while the deformation twins seem to be restricted. The high resolution TEM observation shows some dynamic recrystallization induced nano-sized equiaxed grains with the grain size of no more than $20 \mathrm{~nm}$ within the adiabatic shear band.The twining-induced rotational dynamic recrystallization is proposed to be the main mechanism for initiation andpropagationof adiabatic shear band in the heat-treated 3D laser-deposited Ti-6Al-4V alloy in case of dynamic deformation.

\section{Acknowledgments}

This work was performed under the financial support from the National Science Foundation of China (grant Nos.11522220, 11272267 and11527803) and 111 Project (grant No.B07050) of Northwestern Polytechnical University. 


\section{References}

[1]L. Facchini, E. Magalini, P. Robotti, et al. Rapid Prototyping J. 15(3) (2009) 171-178.

[2]H.J. Gong, K. Rafi, H.F. Gu, et al. Mater. Des. 86 (2015) 545-554

[3]E. Wycisk, C. Emmelmann, S. Siddique, et al. Adv. Mater. Res. 816-817 (2013) 134-139.

[4]F. Wang, S. Williams, P. Colegrove, et al. Metall. Mate.Transa. A. 44(2) (2013) 968-997

[5]L. Facchini, E. Magalini, P. Robotti, et al. Rapid Prototyp. J. 16(16) (2010) 450-459.

[6] S.Y. Zhang, X. Lin, J. Chen, et al.Raremetals. 28(6) (2009) 537-544

[7] B. Vrancken, L. Thijs, J.P. Kruth, et al. J. Alloys Compd. 541(541) (2012) 177-185

[8] L. Zheng, X.P. Ren, H.L. Hou. J. Mater. Res. 30(04) (2015) 566-557

[9] J.Y. Kim, I.O. Shim, S.H. Hong. Int. J. Mod. Phys. B. 22(09n11) (2008)1221-1227.

[10] P.H. Li,W.G. Guo, W.D. Huang, et al. Mater. Sci. Eng. A. 647 (2015) 34-42

[11] H. Kolsky. Proc. R. Soc. Lond. Section B, 62(11) (1949) 676-700

[12]T. Suo, Y.L. Li, K. Xie,et al. Mech. Mater. 43(3) (2011)111-118

[13]A.1. Zhang,D. Liu,X.H, Wu,et al.J.Alloys Compd.585(3)(2014)220-228

[14] Y.Q. Zhao, Y.N. Chen, X.M. Zhang, et al. changsha: Central South University press, 2012.01

[15] J. Zhang, C.W. Tan, Y. Ren, et al. Transactions of Nonferrous Metals Society of China, 21(11)

(2011) $2396-2401$

[16] M.A. Meyers, Wiley, New York 1994: 323-381

[17] T. Suo, Y. Chen, Y.L. Li, et al. Mater. Sci. Eng. A. 560 (2013) 545-551

[18] Y.M Wang, A.V. Hamza, E. Ma. Acta Mater. 54(10) (2006) 2715-2726

[19] T. Suo, Y.L. Li, F. Zhao, ET AL. Mech. Mater. 61(8) (2013) 1-10

[20] J.J. Jonas, R.A. Holt, C.E. Coleman. Acta Metall. 24(10) (1976) 911-918 
[21] S.L. Semiatin, J.J. Jonas. Formability and Workability of Metals, ASM, Materials Park. (1984)

299.

[22] B.F. Wang, J. Li, J.Y. Sun, et al. Mater. Sci. Eng. A. 612 (2014) 227-235

[23] B.F. Wang, Y. Yang. Mater. Sci. Eng. A. 473(1) (2008) 306-311

[24] L. E. Murr, A.C. Ramirez, S.M. Gaytan, et al. Mater. Sci. Eng. A. 516(1) (2009) 205-216

[25] H.A. Grebe, H.R. Pak, M.A. Meyers. Metall. Trans. A. 16(5) (1985) 761-775

[26]M.A. Meyers, V.F. Nesterenko, J.C. LaSalvia, et al. Mater. Sci. Eng. A. 317(1) (2001)

204-225.

[27] Y.B. Xu, W.L. Zhong, Y.J.Chen, et al. Mater. Sci. Eng. A. 299(1) (2001) 287-295.

[28] D.L. Zou, L.Zhen, C.Y Xu, et al. Mater. Charact. 62(5) (2011) 496-502.

[29]H.Q.Sun,Y.N.Shi,M.X.Zhang, et al. Acta Metall. 55(3) (2007) 975-982.

[30] S.N. Medyanika, W.K. Liu, S.F. Li. Journal of the Mechanics and Physics of Solids. 55(7)

(2007) 1439-1461.

[31] D. Rittel, P. Landau, A. Venkert. Phys. Rev. Lett. 101(16) (2008)165501.

[32] D. Rittel. J Phys D: Appl. Phys.42(21)(2009) 214009. 


\section{Table Captions}

Tab. 1 Composition of the Ti-6Al-4V titanium alloy powder (wt \%)

Tab. 2 The parameters of laser solid forming

\section{Figure Captions}

Fig. 1 Schematic illustration of samples preparation for mechanical testing and metallographic

Fig.2. Microstructure of the as-deposited Ti-6Al-4V alloy (a) Side view by optical microscope, (b) the defects on the side surface (parallel to deposition direction), (c) by SEM, (d) top view by SEM.

Fig.3.Microstructure of the heat-treated Ti-6Al-4V alloy (a) the defects on the side surface, (b) and (c) side view by SEM (for (c) light zones are $\beta$ phase, the dark zones are $\alpha$ phase), (d) top view by SEM

Fig.4.True stress-strain curves of the as-deposited and heat-treated Ti-6Al-4V alloy at different strain rates (a) $10^{-3} \mathrm{~s}^{-1}$, (b) $500 \mathrm{~s}^{-1}$, (c) $1500 \mathrm{~s}^{-1}$ and (d) $3000 \mathrm{~s}^{-1}$

Fig.5. Strain hardening rate of materials at different strain rate (a) $10^{-3} \mathrm{~s}^{-1}$ (b) $500 \mathrm{~s}^{-1}$ (c) $1500 \mathrm{~s}^{-1}$ (d) $3000 \mathrm{~s}^{-1}$

Fig.6. Temperature rise of specimens deformed at high strain rates $\left(500 \mathrm{~s}^{-1}, 1500 \mathrm{~s}^{-1}\right.$ and $\left.3000 \mathrm{~s}^{-1}\right)$

Fig.7. True stress versus true strain curve of different strain rates at room temperature (a) as-deposited (b) heat-treated

Fig. 8 The function of true stress at true strain of $8 \%$ versus strain rate plot for both as-deposited and heat-treated 3D laser-deposited Ti-6Al-4V alloy 
Fig. 9 Fracture morphology of Ti-6Al-4V alloy after dynamic compression (a) as-deposited alloy at the strain rate of $1500 \mathrm{~s}^{-1}$, (b) heat-treated alloy at the strain rate of $1500 \mathrm{~s}^{-1}$, (c) as-deposited alloy at the strain rate of $3000 \mathrm{~s}^{-1}$, (d) heat-treated alloy at the strain rate of $3000 \mathrm{~s}^{-1}$

Fig.10 SEM micrographs of shear band of the heat-treated alloy after quasi-static and dynamic compression (a) quasi-static (strain rate of $10^{-3} \mathrm{~s}^{-1}$ ), (b) dynamic (strain rate of $1500 \mathrm{~s}^{-1}$ )

Fig. 11 Schematic illustration of TEM sample preparation using FIB

Fig. 12 TEM observation of microstructure inside the shear band for heat-treated specimens deformed at the strain rate of (a) $0.001 \mathrm{~s}^{-1}$, (b) and (c) $1500 \mathrm{~s}^{-1}$ 